\begin{tabular}{|c|c|}
\hline Title & Why Did a Female Penis Evolve in a Small Group of Cave Insects? \\
\hline Author(s) & Y oshizawa, Kazunori; Ferreira, Rodrigo L.; Lienhard, Charles; Kamimura, Y oshitaka \\
\hline Citation & $\begin{array}{l}\text { Bioessays, 41(6), 1900005 } \\
\text { https://doi.org/10.1002/bies.201900005 }\end{array}$ \\
\hline Issue Date & 2019-06 \\
\hline Doc URL & http:/hdl.handle.net/2115/78286 \\
\hline Rights & $\begin{array}{l}\text { This is the peer reviewed version of the following article: Why Did a Female Penis Evolve in a Small Group of Cave } \\
\text { Insects?; Bioessay s } 41(6), \text { June 2019, which has been published in final form at } \\
\text { https://doi.org/10.1002/bies.201900005. This article may be used for non-commercial purposes in accordance with } \\
\text { Wiley Terms and Conditions for U se of Self-A rchived V ersions. }\end{array}$ \\
\hline Tyре & article (author version) \\
\hline File Information & BioEssays.rev1.final.pdf \\
\hline
\end{tabular}

Instructions for use 


\section{Why did a female penis evolve in a small group of cave insects?}

Kazunori Yoshizawa, Rodrigo L Ferreira, Charles Lienhard and Yoshitaka Kamimura

Assoc. Prof. K. Yoshizawa

Systematic Entomology

School of Agriculture

Hokkaido University

Sapporo 060-8589, Japan

E-mail: psocid@res.agr.hokudai.ac.jp

Prof. R. L. Ferreira

Biology Department

Federal University of Lavras

CEP 37200-000 Lavras (MG), Brazil

Dr. C. Lienhard

Geneva Natural History Museum

CP 6434, 1211 Geneva 6, Switzerland

Assoc. Prof. Y. Kamimura

Department of Biology

Keio University

Yokohama 223-8521, Japan

E-mail:kamimura@fbc.keio.ac.jp 


\section{Abstract}

The evolution of a female penis is an extremely rare event and is only known to have occurred in a tribe of small cave insects, Sensitibillini (Psocodea: Trogiomorpha: Prionoglarididae). The female penis, which is protrudable and inserted into the male vagina-like cavity during copulation to receive semen, is thought to have evolved independently twice in this tribe, in the Brazilian Neotrogla and the African Afrotrogla. These findings strongly suggest that there are some factors unique to Sensitibillini that have facilitated the female penis evolution. Here, we present several hypothetical factors that may have enabled the evolution of female penis in Sensitibillini. The female-female competition for nutritious semen, the oligotrophic environment, and the twin insemination slots with switching valve are considered to be the driving factors of the female penis evolution. Additionally, the following factors are considered responsible for relaxing the constraint against female penis evolution: pre-existence of the female-above mating position, the elongated duct connecting the female pre-penis with the sperm storage organ, and the small male genital cavity accepting the female genital tubercle bearing the opening of this duct. Understanding the factors enabling female penis evolution may also shed light on the evolution of the male penis. 


\section{Introduction}

The "penis" is defined as "the male genital organ of higher vertebrates..." or "a type of male copulatory organ present in some invertebrates" (Oxford Dictionary of English). Therefore, the discovery of the "female" penis (termed gynosome [1]) in the Brazilian cave insect genus Neotrogla (Psocodea: "Psocoptera": Trogiomorpha: Prionoglarididae: Sensitibillini; Figs 1,2A) received substantial attention [2]. The female penis is protrudable and inserted into the male vaginalike cavity during copulation to receive semen from the male. A female penis has also been identified in the African Sensitibillini genus Afrotrogla [3]. Due to the systematic position of these two genera (a taxon without female penis, Sensitibilla, is placed as the sister of Afrotrogla: Fig. 1A) and significant differences in the female penis morphology between Afrotrogla and Neotrogla (Fig. $1 \mathrm{C}-\mathrm{D})$, the female penis is considered to have evolved independently twice in this small tribe of cave insects containing eleven named species only [4]. The female penis of these insects shows many analogous features with the male penis in general: it is protrudable, inserted into the receptive organ of the opposite sex for sperm transfer and, as observed in some insects [5], bears spines to anchor the mate (Fig. 2C). The rapid evolution of species-specific male genital morphologies, including those of the penises, has been recognized for over a century [6]. The female penis of Afrotrogla and Neotrogla is also highly divergent between closely related species and thus is used as the most important character for diagnosing species [1,7], as is the case for male penis in other insects [8].

It is widely accepted that sexual selection underlies the great divergences of genitalia. By definition, spermatozoa are smaller than ova; thus, the fitness of males, who can provide a required number of spermatozoa to multiple females, is expected to linearly increase with the number of mates. In contrast, mating with multiple mates is not generally beneficial for females, whose fitness is limited by the number of ova, and multiple mating could even be detrimental [9]. This fundamental difference between the sexes usually results in much stronger sexual selection against males: i.e., male-male competition for acquiring mates, and choosiness in females stronger than in males when selecting mates [10,11]. Furthermore, sperm competition, that is the competition between the spermatozoa of different males for the fertilization of a given set of ova, inevitably arises when females (at least potentially) mate with multiple males [12]. Females, who own the arena for sperm competition, can also actively modulate sperm transfer, sperm storage and sperm usage patterns, thereby biasing paternity (cryptic female choice) $[13,14]$. Therefore, sexual selection acts also in post-copulatory phases resulting in exaggerated male genitalia, such as those with elaborate spines that are used to remove rival sperm from the female sperm storage organ, those with a titillating function for efficient sperm transfer or those penises used for securely anchoring mates against take-over of mating by other males [5,15-19]. 
Sexual conflict over mating is also considered an important force underlying the rapid coevolution of male and female genital structures [18,20-22]. Because females usually have a lower optimal rate of remating and thus are choosier than males, males frequently develop a trait of "persistence" in their genitalia, such as sharply pointed spines for grasping unwilling mates, or those for making wounds in the female genital tract serving as the entrances of manipulative seminal substances into the female blood system [17,23]. For mitigating the costs imposed by these male persistence traits, females develop traits for "resistance" or "tolerance" in their genitalia as counter-adaptation, such as thickened walls or membranous pouches for contacting with or accommodating male genital spines [5,17,24]. Interestingly, the female penis of Neotrogla bears species-specific spines, and corresponding to them, the males have membranous pouches in their vagina-like genitalia $[2,4]$. Thus, not only the sex bearing a penis, but also the pattern of genital coevolution is totally reversed in Neotrogla.

Some male animals donate nutritious substances or preys to females during mating (nuptial gifts [25]). Because it can enhance the fitness of female recipients while imposing a preparation cost to males at the same time, donation of nuptial gifts can reverse the optimal rate of remating and the associated sex roles between the sexes (sex role reversal $[10,26])$. For example, females are more active for mating and males are choosier in some dance flies (Diptera: Empididae) where males donate prey items to females, indicating that the direction of sexual selection is reversed in these animals [27]. The ground weta (Orthoptera: Anostostomatidae: Hemiandrus pallitarsis) is an illustrative case. Females of this species benefit from seminal gifts from males and compete intensely for these gifts using an elbow-shaped structure located in the middle of the abdomen [28].

As discussed below, sex-role reversal due to donation of nuptial gifts is also considered to be the most important factor driving the evolution of the female penis in Sensitibillini [2]. There are considerable numbers of animals showing sex-role reversal in competition for mates but, except for Sensitibillini, all of these animals known to date have normal copulatory organs including the case of the ground weta [28]. Seahorses and pipefish (Pisces: Syngnathidae) are known for the reversals in the parental roles: males experience "pregnancy" by caring broods in a specialized pouch on the ventral side of the abdomen [29]. Although the females possess a penis-like tube, it is an ovipositor for depositing eggs into the male pouch [30]. The females of spotted hyena (Crocuta crocuta) are also famous for having an enlarged, erectile penis-like clitoris, referred to as a pseudo-penis [31]. However, male spotted hyenas insert the penis to the pseudo-penis of the mate for copulation [32]. Therefore, any of these penis-like organs do not represent a true intromittent organ used for seminal transfer.

It is very likely that there are some factors unique to Sensitibillini that have enabled the unique reversal of genital organs. The available information about the mating behavior of 
Sensitibillini is still limited. However, based on other biological information, we have developed several hypotheses about the factors that are unique to this group of insects and may have been crucial for the evolution of the female penis. Here, we discuss these hypothetical factors including preliminary results of an ongoing analysis.

\section{Reversed sexual selection and its reinforcement}

The factors related to the evolution of the female penis can be classified into two categories: the factors favoring the evolution of a female penis and the factors constraining the evolution of a female penis. First, we discuss the factors favoring the female penis evolution.

\subsection{Nutritious semen}

The sex-role reversal caused by female-female competition for nutritious semen is considered to be the most important evolutionary pressure favoring the origin of the female penis [2]. In a close relative of Sensitibillini (Trogiidae: Lepinotus), it has been confirmed that females compete for mating opportunities to acquire seminal substances [33]. The delivered semen forms capsuleshaped spermatophores within the female's sperm storage organ (spermatheca). The mechanism of the capsule formation is least understood but is speculated to be initiated either by substances provided by the male, protective response of the female against the semen, or by a chemical reaction between the semen and spermathecal fluid [34,35]. The content of the capsule is digested and consumed within the spermatheca by the female. After consumption, the empty capsules remain within the spermatheca. The frequent existence of multiple capsules shows that the females mate with multiple males [34]. Possession of multiple capsules has also been observed in other Trogiomorpha [36].

Our previous observations strongly suggested that female-female competition for nutritious semen also exists in Sensitibillini. Similar gigantic seminal capsules, as observed in Lepinotus, are found in all members of Sensitibillini (Figs 2D, 3A) [1,3,37]. The volume of a single spermatophore of Neotrogla is estimated to be $\sim 0.05 \mathrm{~mm}^{3}$, corresponding to $\sim 300 \mathrm{ml}$ scaled up to humans [38]. Females frequently possess multiple seminal capsules, indicating that they mate with multiple males [1,2]. Judging from their genital structures, the females must actively control this multiple mating. We also confirmed that female Neotrogla consume the semen outside of fertilization [2]. These lines of circumstantial evidence strongly suggest the female's consumption of semen for nutrition and the presence of sex-role reversal in Sensitibillini, but direct evidence is still unavailable. The female's usage of semen can be tested by observing the movement of malederived substances within female body by labelling them using fluorescent dye or isotope, and the presence of sex-role reversal can be tested by mate choice experiments. Here we accept the 
assumption about the female's consumption of the nutritious semen.

\subsection{Oligotrophic environment}

The unique habitats of Sensitibillini likely strengthen the female-female competition for nutritious semen $[2,4]$. The caves inhabited by Neotrogla are all very dry and poor in food resources (oligotrophic) [4,7]. Recently (November 2018), RLF conducted field work in Namibian caves inhabited by Sensitibilla and Afrotrogla and confirmed that these caves are also very dry and oligotrophic, presenting extremely similar conditions to those observed in the caves where Neotrogla species are found. Under such an environment, females' demands for seminal nutrition may be strengthened compared to sex-role reversed animals inhabiting a nutrition-rich environment, rendering more intense female-female competition for semen in Sensitibillini.

This hypothesis can be tested by comparative studies between closely related taxa inhabiting cave/non-cave environments. For example, the habitat of the sister taxon of Sensitibillini (Speleketor) is also very dry. One of the species (Speleketor irwini) is known to inhabit dried dead leaves of the desert fan palm (Washingtonia filifera) [39]. However, dried dead leaves are widely utilized by many insects, and the environment inhabited by Speleketor is probably less oligotrophic. The quantitative analyses of their inhabiting environments and comparisons of their demands for nutritious semen will clarify the strength of the female-female competition against semen. Several additional pairs of cave/non-cave inhabiting taxa that can be used for comparative studies for testing this hypothesis are also available in psocopterans [40].

\subsection{Twin slots for nuptial gifts and a switching valve}

The presence of a specialized spermathecal plate unique to Sensitibillini (Fig. 3) is considered to be an additional key and novel feature that is tightly associated with the evolution of the female penis [38]. The spermathecal plate possesses two slots for keeping two spermatophores containing seminal gifts (seminal capsules: Fig. 3AB) and a switching valve system, consisting of the closure element and associated muscles (Fig. 3B-D), for controlling seminal flow toward one of the two slots (Fig. 3B) by leaning the closure element.

The condition of keeping two freshly deposited spermatophores at once may be comparable to that in multiple sperm storage organs reported for females of some animals [41-43]. Having multiple sperm storages can be a powerful mechanism for choosing sperm from multiple males for genetic benefits (i.e., choosing sperm from high-quality males) [44]. However, as mentioned above, Neotrogla and the related species consume the content of the seminal capsule as nutrition quite rapidly, if not used for fertilization [34,38]. Therefore, the switching valve system likely represents an adaptation for direct benefits (i.e., for obtaining more nutrients) rather than for genetic benefits. 
Consumption of the spermatophore contents is done when the capsule is attached to the junction between the proximal end of the spermathecal duct and the spermathecal pouch $[34,38]$. Therefore, if there is only one slot, females cannot receive a second seminal gift while digesting another. With the spermathecal plate and switching valve, the females of Neotrogla (and possibly those of other Sensitibillini) can selectively use one of two slots for insemination, leaving the other slot empty. This enables the female to immediately receive an additional gift from the same or another male. Therefore, she has the potential to receive double the amount of nutritious semen simultaneously compared to the species lacking the switching valve. Thus, this innovation likely renders female-female competition for seminal gifts more intense, favoring the evolution of a female penis with a mate-grasping function.

To test this hypothesis, we performed an individual-based computer simulation (Kamimura et al., in prep.). In this model, we made several assumptions on the ecology and life history of Sensitibillini species. First, male paternity benefits are considered to increase with the seminal gift size because females will remate only after digestion of the gift content when all the slots are occupied. However, because of resource-limitation in oligotrophic environments, males who produce a large gift can mate fewer times. Second, we can assume some costs for female multiple mating, such as those for mate searching. Therefore, for females, a few large gifts are better than many smaller ones of the equivalent total volume. Our preliminary results suggested that females with two insemination slots can easily invade a population of the ancestral one-slot state owing to their advantages in acquiring nuptial gifts in rapid succession. Given that the total amount of malederived nutrition is constant, the evolution of the two-slot state could result in an increase in the variance of female fitness, i.e., escalated sexual selection among females. The model assumptions should be empirically tested in future studies. Especially, we assumed that males pass only one spermatophore during a single mating bout, and thus females with twin slots must search for a new mate for another seminal capsule. However, if females can coerce each male mate to pass two spermatophores during a single copulation bout (by securely grasping him with the thorny female penis), it may drastically reduce the mate searching cost. Highly polymorphic microsatellite markers developed for Neotrogla species [45] can be powerful tools for determining the donors of two fresh spermatophores in a female spermatheca (as shown in Fig. 2D) in future studies.

\section{Relaxed constraints against genital reversal}

Even with strong selective pressures favoring the female penis, many constraints exist. To overcome such constraints, some morphological and behavioral factors are prerequisites. In the following section, we note the potential preadaptive features observed in Sensitibillini. 


\subsection{Female-above mating}

When we presented a photograph of the female-above mating (i.e., a female mounting on a male) of Neotrogla (Fig. 2A [2]), this was widely misrecognized as a reversed mating position. However, contrary to this assumption, the female-above mating position is an ancestral state for insects [46], and many psocopterans simply retain it (Fig. 2B).

Mating positions are thought to affect the evolution of insect genital traits [46]. Bush crickets and ground crickets also retain the ancestral female-above mating positions. It is well known that male crickets use courtship songs to attract mates. To make females climb on their back, males of some species need further attractants, such as nutritious secretion from the male's dorsum [47]. In contrast, in insects with male-above mating positions (bees, water striders, bedbugs and so on), males can play more active roles in initiation of genital couplings, including coercive insertion of the penis [48]. Potentially coercive anchoring by females as observed in Neotrogla might be difficult to evolve in passive females of animals with male-above mating positions (but see also [49] for an exceptional case). It is likely that the female-above mating position retained in psocopterans allowed the evolution of female-led mating in Sensitibillini. Further investigations of the courtship and coupling behaviors of Sensitibillini are needed to confirm whether females are able to actively control the initiation and duration of copulation, even when it is costly to the male mate.

\subsection{Elongated spermathecal duct}

An insect penis is telescopic in structure and thus is stored in the abdomen when in repose and is protruded for copulation. The female penis of Neotrogla and Afrotrogla (Figs 2C, 4B) also shares these characteristics. The length of the female penis in Neotrogla reaches over $20 \%$ of the female's total body length so that the range of penile movement is also quite wide.

The female penis of Neotrogla and Afrotrogla is used for receiving semen from the males. Therefore, it is continuous to the spermatheca via a duct (spermathecal duct) opening at the tip of the female penis (spermapore). Among the three psocopteran suborders, the spermatheca of psocomorphans and troctomorphans is generally situated close to the spermapore and connected to it by a relatively short duct $[50,51]$. With this condition, a protrudable penis cannot evolve because the spermatheca and its short duct will disturb the movements of a telescopic penis.

In contrast, long and narrow spermathecal ducts can be frequently seen in Trogiomorpha [50,51]. This is especially true for Sensitibillini [7,37]: the spermatheca is located far from the spermapore, and the spermathecal duct is narrow, extremely elongated, and spirally coiled (Fig. 4B). Only with this duct condition, wide range of the penile movement becomes possible without altering the spermathecal position within the female abdomen. Such a condition is detected even in 
Sensitibilla lacking a protrudable female penis (Fig. 4A) [37]. In contrast, the spermathecal duct of Speleketor, the sister taxon of Sensitibillini (Fig. 1A), is very short [3]. This indicates that this condition evolved in the common ancestor of Sensitibillini, relaxing the constraint against the female penis evolution. It is probable that the evolution of a protrudable male penis is also constrained by its connection with the testis. Though the effect of the elongated spermathecal duct on the evolution of a female penis in Sensitibillini is difficult to test, comparisons of the male's seminal duct condition between insect taxa with/without protrudable male penis may provide a clue to elucidate the constraint coming from the internal structures on the evolution of intromittent organs.

The narrow and notably elongated spermathecal duct of Sensitibillini likely disturbs rapid seminal transfer. Together with the duplicated slots, this morphology probably causes the very long copulation period (40 to 70 hours) in Neotrogla [2]. Comparatively long and narrow spermathecal ducts of Trogiomorpha, in which formation of gigantic spermatophores is the norm, might function as a counteradaptation for cheating by males. Males of the hangingfly Hylobittacus apicalis (Mecoptera: Bittacidae) donate their prey (small insects) to females as nuptial gifts. Females accept mating only while eating a gift. Their narrow and elongated spermathecal duct disturbs rapid sperm transfer from males. Therefore, only males that offer a large prey item are able to transfer enough sperm to assure their paternity [52]. If a spermathecal duct is wide and short, enabling rapid transfer of sperm, males may easily evolve a cheating strategy such that they pass a large number of spermatozoa with a minimal nuptial gift [53]. Note that the narrow corridor for sperm can function not only as a restraint on male cheats but also as a selective receptacle for sperm from superior males who can prepare and honestly provide large gifts (cryptic female choice [52]). The high level of diversity in spermatophore size and spermathecal morphology of Psocodea offers a significant opportunity to test these hypothetical functions.

\subsection{Absence of male penetrative organ and presence of tubercle-grasping coupling}

Drastic morphological changes of female genitalia, such as the evolution of a female penis, must be accompanied by the concerted evolution of corresponding male genitalia. In other words, modification of a bulging male intromittent organ into an emarginated vagina must be accomplished to accept the penetration of a female penis. Recent studies on Drosophila fruitfly species showed that slight mismatches between male and female genital morphologies during coupling can cause leakage of ejaculates, which results in a prolonged struggle to separate pairs glued together by dried semen [54,55]. Given that the semen is voluminous and possibly reactive in Sensitibillini and the allied taxa (see Section 2.1), a precise and tight coupling of male and female genitalia is probably important also in this group of insects. Therefore, even if possession of a penis 
is highly beneficial for females, evolution of such a structure must be strongly constrained by the presence of a male penis (or a corresponding intromittent structure), which needs concerted evolutionary changes with the female genitalia.

However, not all animals possess a male penis and a female vagina. In most bird species, insemination is accomplished by the close contact between male and female cloacae (the terminal opening of the digestive and urinary systems, also used for insemination and egg laying): the structure of cloacae is almost identical in both sexes [56]. In psocopterans, the seminal transfer is generally achieved by tight contact between the flat spermapore plate (the plate surrounding the spermapore) situated in the female genital cavity and a non-bulging and membranous opening of the male seminal duct [50,57]. Furthermore, the tight contact between the seminal inlet and outlet openings is achieved not by insertion of the male penis but by hooking and pulling out the spermapore plate from the female genital chamber toward the male seminal outlet opening by using some non-penile structures of the male terminalia, the epiproct in Lachesilla (Lachesillidae) [50] or the 9th sternum in Trichadenotecnum (Psocidae) [57], both belonging to the suborder Psocomorpha. Therefore, it is very likely that, in the most ancestral condition, the psocid males did not have an intromittent organ.

Furthermore, in a close relative of Sensitibillini (Trogiidae: Trogium), the females spermapore plate is modified into a small tubercle. During copulation, the males grasp the tubercle by using the parameres (the structure generally presented next to the male penis that is used to hold a female during copulation) (Fig. 4D) [50]. Therefore, even in a species with regular male genitalia, the small female organ slightly penetrates the male genitalia. In addition, based on the observation of coupling condition in Trogium, slight but active erection of the spermapore tubercle due to the pressure of female body fluid has also been speculated [50]. Female tubercles are widely observed in Trogiomorpha [51,58], including the genus Speleketor, the sister taxon of Sensitibillini with regular genital structures (Fig. 4C) [3]. This strongly suggests that, preceding the evolution of a female penis, a small cavity for accepting the female's tiny projection existed in the male genitalia of Trogiomorpha, relaxing the constraint against the evolution of a female penis.

The next key novelty concerning this tubercle, before the origin of a female penis, is the evolution of a sclerotized internal shaft and associated muscles as observed in the genus Sensitibilla (Fig. 4A: pre-penis). At this stage, the tubercle still does not form a protruding structure, as observed in Neotrogla and Afrotrogla [4]. In comparison to the high morphological variation of the female penis in Neotrogla and Afrotrogla, the interspecific variation of the pre-penis of Sensitibilla, as well as the tubercles of other trogiomorphans, is very low $[3,37,51,59]$. This suggests that the shape of the tubercle has not been subjected to strong sexual selection, which may provide a key difference between the female penis and pre-penis. However, a significant reduction of the 
parameres (which are completely and convergently absent in Neotrogla and Afrotrogla [4]) can also be detected in Sensitibilla [3,59]. Therefore, the change of the coupling mode (i.e., without tubercle grasping) most likely evolved in the common ancestor of Sensitibillini, which might have led to the evolution of the female penis. The muscles attached to the internal shaft are used to retract the female penis in Neotrogla and Afrotrogla, but the origin and function of the internal shaft and associated muscles of Sensitibilla are now under investigation.

\section{Summary and perspectives}

Nikolaas Tinbergen, who won the Nobel Prize in 1973 as one of the founders of ethology, emphasized that we can answer the "why" questions of evolutionary biology in four different ways [60]. By answering Tinbergen's four questions, the above-mentioned factors related to the female penis evolution can be summarized as follow:

Q1 Mechanism - The female penis is telescopic and protrudable to penetrate and anchor a male during copulation (potentially coercively) [2]. To achieve this mechanism, the female-above mating position (Section 3.1) and substantially elongated and coiled spermathecal duct (Sec. 3.2) were crucial.

Q2 Development - The female penis is originated by modification of the spermapore plate (Sec. 3.3), but its developmental pathway, including genetic background, are least understood and thus require further studies.

Q3 Adaptation - By using the female penis, females can actively control the initiation and duration of copulation to obtain more nutritious semen from males (Sec. 2.1). Females' strong demands for the nutritious semen probably caused intense female-female mating competition, which is further strengthened by their oligotrophic habitat (Sec. 2.2) and their ability to obtain double amount of semen using the twin seminal slots (Sec. 2.3).

Q4 Phylogeny - The female penis has originated twice independently in Afrotrogla and Neotrogla respectively, through a series of modifications of the spermapore plate: from an ancestral flattened condition through tubercle (as seen in trogiomorphans including Speleketor) and pre-penis (as seen in Sensitibilla) (Sec. 3.3).

Assumed evolutionary history of these features are mapped on the phylogenetic tree recently estimated from the combination of nuclear and mitochondrial genes (Fig. 1) [4]. Some of these features probably already existed in the ancestors of Trogiomorpha or Psocodea. However, over half of the key innovations were estimated to have evolved in the common ancestor of Sensitibillini. The function of such already existed innovations is less understood, and the relationships between those innovations and the evolution of a female penis are still hypothetical. Other factors not mentioned above, such as the tarsal trichobothria (sensory organs), which are also 
unique to Sensitibillini among insects [1,3,59], may also have some relation to their mating behavior (e.g., rapid recognition of predator during long copulation, because mating pairs may experience higher predation risk). Further investigations are needed to elucidate the origin and evolution of the female penis.

Male penises also have evolved multiple times [61]. They are used for transferring spermatozoa, which are tiny and vulnerable to dryness, towards the female reproductive tract. Nevertheless, not all terrestrial animals possess a penis, warranting examination of conditions that promote the evolution of intromittent organs in general. Understanding the factors enabling the evolution of the female penis may also shed light on the evolution of the male penis. 


\section{Acknowledgements}

This study was partly supported by the JSPS research grant $15 \mathrm{H} 04409$ to KY and YK and CNPq 304682/2014-4 to RLF.

\section{Conflict of Interests}

The authors declare no conflicts of interest.

\section{Keywords}

sexual selection, sex-role reversal, genital evolution, Sensitibillini, Neotrogla, Afrotrogla

\section{References}

[1] C. Lienhard, T. O. Do Carmo, R. L. Ferreira, Rev. suiss. Zool. 2010, 117, 611.

[2] K. Yoshizawa, R. L. Ferreira, Y. Kamimura, C. Lienhard. Curr. Biol. 2014, 24, 1006.

[3] C. Lienhard, Rev. suiss. Zool. 2007, 114, 441.

[4] K. Yoshizawa, R. L. Ferreira, I. Yao, C. Lienhard, Y. Kamimura. Biol. Lett. 2018, 14, 20180533.

[5] J. Rönn, M. Katvala, G. Arnqvist. 2007, 104, 10921.

[6] W. G. Eberhard. Sexual Selection and Animal Genitalia, Harvard Univ. Press, Cambridge 1985, p. 244.

[7] C. Lienhard, R. L. Ferreira, Rev. suiss. Zool. 2013, 120, 3.

[8] S. L. Tuxen. Taxonomist's Glossary of Genitalia in Insects, 2nd ed, Munksgaard, Copenhagen 1970, p. 359.

[9] A. J. Bateman. Heredity 1948, 2, 349.

[10] R. Trivers, in Sexual Selection and the Descent of Man 1871-1971 (Ed: B. Campbell) Aldine Press, Chicago 1972, pp. 139-179.

[11] M. B. Andersson. Sexual Selection. Princeton Univ. Press, Princeton 1994, p. 624.

[12] G. A. Parker. Biol. Rev. 1970, 45, 525.

[13] R. Thornhill. Am. Nat. 1983, 122, 765.

[14] W. G. Eberhard. Female Control: Sexual Selection by Cryptic Female Choice. Princeton Univ. Press, Princeton 1996, p. 472.

[15] J. K. Waage. Science 1979, 203, 916.

[16] D. J. Hosken, P. Stockley. Trends Ecol. Evol. 2004, 19, 87.

[17] K. Reinhardt, N. Anthes, R. Lange, in The Genetics and Biology of Sexual Conflict (Eds: W. R. Rice, S. Gavrilets). Cold Spring Harbor Laboratory Press, New York 2014, pp. 115-139.

[18] L. W. Simmons. Aust. Entomol. 2014, 53, 1. 
[19] A. V. Peretti, A. Aisenberg. Cryptic Female Choice in Arthropods - Patterns, Mechanisms and Prospects. Springer, Cham 2015, p. 496.

[20] D. J. Hosken, P. Stockley. Trends Ecol. Evol. 2004, 19, 87.

[21] G. Arnqvist, L. Rowe. Sexual Conflict. Princeton Univ. Press, Princeton, 2005, p. 352.

[22] P. L. R. Brennan, R. O. Prum, in The Genetics and Biology of Sexual Conflict (Eds: W. R. Rice,

S. Gavrilets) Cold Spring Harbor Laboratory Press, New York 2014, pp. 385-405.

[23] C. Hotzy, M. Polak, J. L. Rönn, G. Arnqvist, G. Curr. Biol. 2012, 22, 2258.

[24] Y. Kamimura. Evolution 2016, 70, 1674.

[25] S. Lewis, A. South, in Advances in the Study of Behavior, Vol. 44 (Eds: H. J. Brockmann et al.), Elsevier, Amsterdam, 2012, pp. 53-97.

[26] Y. Kamimura, K. Yoshizawa, in Encyclopedia of Animal Cognition and Behavior (Eds: J. Vonk, T. K. Shackelford), Springer, Cham 2017, DOI:10.1007/978-3-319-47829-6_2012-1.

[27] L. F. Bussière, D. T. Gwynne, R. Brooks. J. Evol. Biol. 2008, 21, 1683.

[28] D. T. Gwynne. Biol. J. Linn. Soc. 2005, 85, 463.

[29] E. S. Herald. Proc. Calif. Acad. Sci. 1959, 29, 465.

[30] W. G. Williams. Sex and Evolution. Princeton Univ. Press, Princeton 1975, p. 210.

[31] B. Schmotzer, A. Zimmermann. Anat. Anz. 1922, 55, 257.

[32] M. Szykman, R. Van Horn, A. Engh, E. Boydston, K. Holekamp. Behaviour 2007, 144, 815.

[33] J. Wearing-Wilde. J. Ins. Behav. 1996, 9, 599.

[34] J. Wearing-Wilde. Tissue Cell 1995, 27, 447.

[35] K. Yoshizawa, Y. Kamimura, C. Lienhard, R. L. Ferreira, A. Blanke. eLife 2018, DOI:10.7554/eLife.39563.013.

[36] C. Lienhard, R. L. Ferreira. Rev. suisse Zool. 2014, 121, 211.

[37] C. Lienhard, Rev. suiss. Zool. 2000, 107, 871.

[38] K. Yoshizawa, Y. Kamimura, C. Lienhard, R. L. Ferreira, A. Blanke. eLife 2018, 7, e39563.

[39] E. L. Mockford, North American Psocoptera, CRC Press, Florida 1993, p. 480.

[40] C. Lienhard, R. L. Ferreira. Rev. suisse Zool. 2015, 122, 121.

[41] P. Ward. Behav. Ecol. Sociobiol. 1993, 32, 313.

[42]. Pitnick, T. Marrow, G. S. Spicer. Evolution 1999, 53, 1804.

[43] E. Twig, B. Yuval. J. Ins. Physiol. 2005, 51, 67.

[44] B. Hellriegel, P. I. Ward. J. Theoret. Biol. 1998, 190, 179.

[45] Y. Kamimura, J. Abe, R. L. Ferreira, K. Yoshizawa. Entomol. Sci. 2019, 22, 48.

[46] B. A. Huber, B. J. Sinclair, M. Schmitt. Biol. Rev. 2007, 82, 647.

[47] C. L. Boggs, in Insect reproduction (Eds: S. R. Leather, J. Hardle), CRC Press, Florida 2018, pp. 215-242. 
[48] M. T. Siva-Jothy. Phil. Trans. R. Soc. B. 2006, 361, 269.

[49] K. Vahed. Ethology 2002,108, 1065.

[50] E. Klier, Zool. Jb. (Anatomie)1956, 75, 207.

[51] C. Lienhard, Psocoptères Euro-Méditerranéens, Faune de France, Paris 1998, p. xx+517.

[52] R. Thornhill. Am. Nat. 1976, 110, 529.

[53] R. Noë, P. Hammerstein. Behav. Ecol. Sociobiol. 1994, 35, 1.

[54] Y. Kamimura, H. Mitsumoto. Entomol. Sci. 2012, 15, 197.

[55] K. M. Tanaka, Y. Kamimura, A. Takahashi. Evolution. 2018, 72, 2406.

[56] K. C. Klasing. Seminars Avian Exotic Pet Med. 1999, 8, 42.

[57] Z. Cheng, K. Yoshizawa. J. Morph. 2019, DOI:10.1002/jmor.209605.

[58] C. Lienhard, R. L. Ferreira. Rev. suiss. Zool. 2013, 120, 421.

[59] C. Lienhard, O. Holuša, G. Grafitti, Rev. suiss. Zool. 2010, 117, 185.

[60] N. Tinbergen. Zeit. Tierpsychol. 1963, 1963, 410.

[61] D. A. Kelly. Proc. R. Soc. B. Suppl. 2004, 271, S293. 
Figure captions

Figure 1. A) Phylogenetic position and relationships of Sensitibillini [4]. Evolutionary transitions potentially related to the origin of female penis are mentioned. B-D) Female pre-penis/penis of Sensitibilla etosha (B), Afrotrogla oryx (C), and Neotrogla aurora (D) (approximately to scale, homologous structures indicated by the same color).

Figure 2. A) Neotrogla sp. in copula, body length approximately $3 \mathrm{~mm}$ (copulation occurred on the ceiling of a cave; the image upside down). B) Trichadenotecnum incognitum (Psocomorpha) in copula, body length approximately $3 \mathrm{~mm}$ (fixed specimens). C) Terminal abdomen of $N$. aurora, showing an artificially exposed female penis. D) Spermatheca of $N$. truncata fixed during copulation. Seven seminal capsules, including two filled capsules attached to the switching valve system, are present.

Figure 3. Spermathecal switching valve system of Neotrogla [38]. A) Light microscopy photograph of the spermathecal plate with a single seminal capsule. B) 3D segmentation of the switching valve system with two seminal capsules, showing seminal flow. C) Photograph taken with a Confocal Laser Scanning Microscope. D) 3D segmentation of the closure element and surrounding structures.

Figure 4. A) Terminal abdomen of Sensitibilla etosha, showing pre-penis. B) Terminal abdomen of N. aurora, showing female penis in repose (same individual as shown in Fig. 2C). In A and B, the elongated spermathecal duct is indicated by arrowheads. C) Spermapore tubercle of Speleketor irwini. D) Genital coupling of Trogium pulsatorium. Male structures are highlighted by blue and female structures by red (redrawn from Klier [50]). 


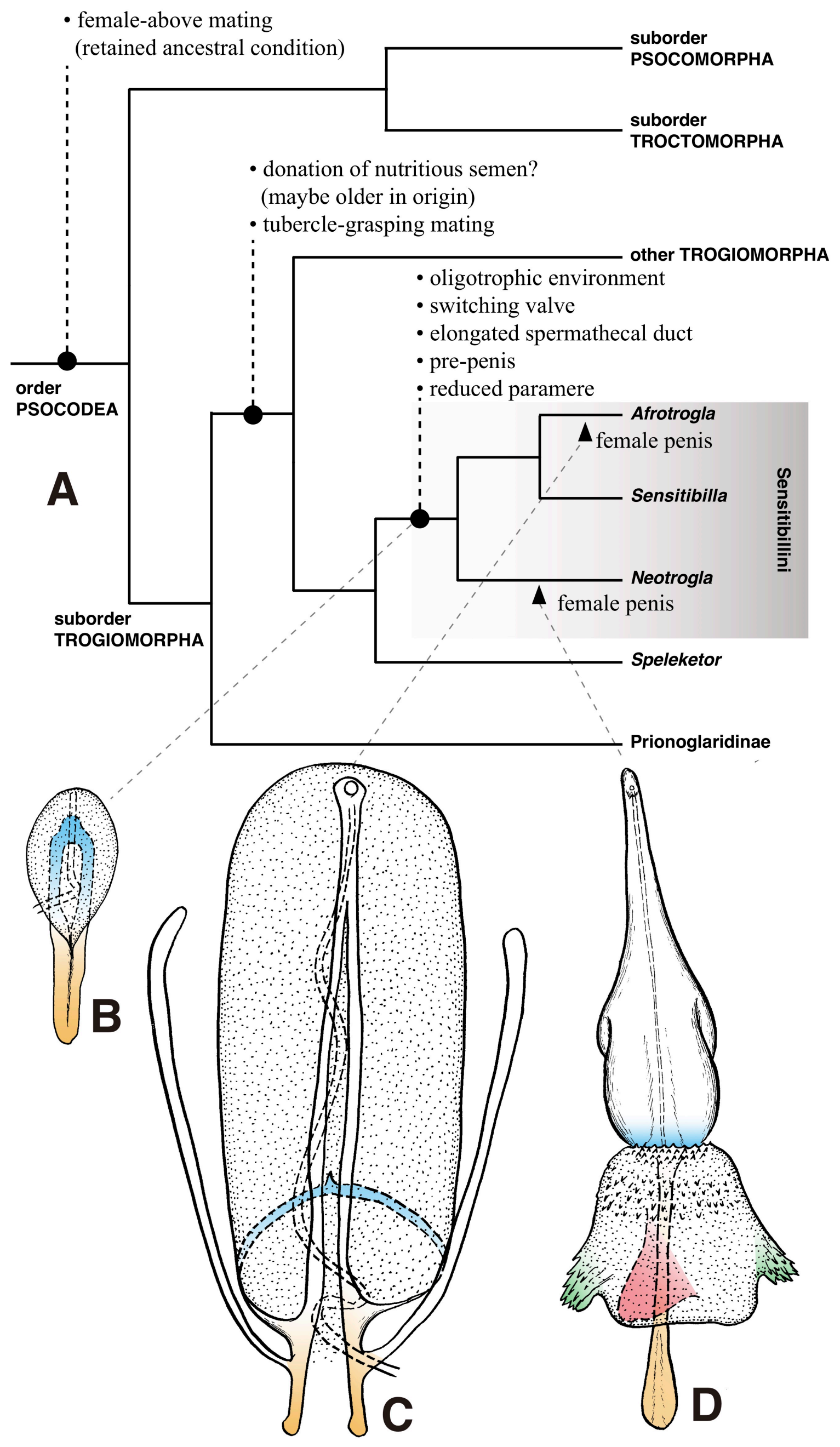



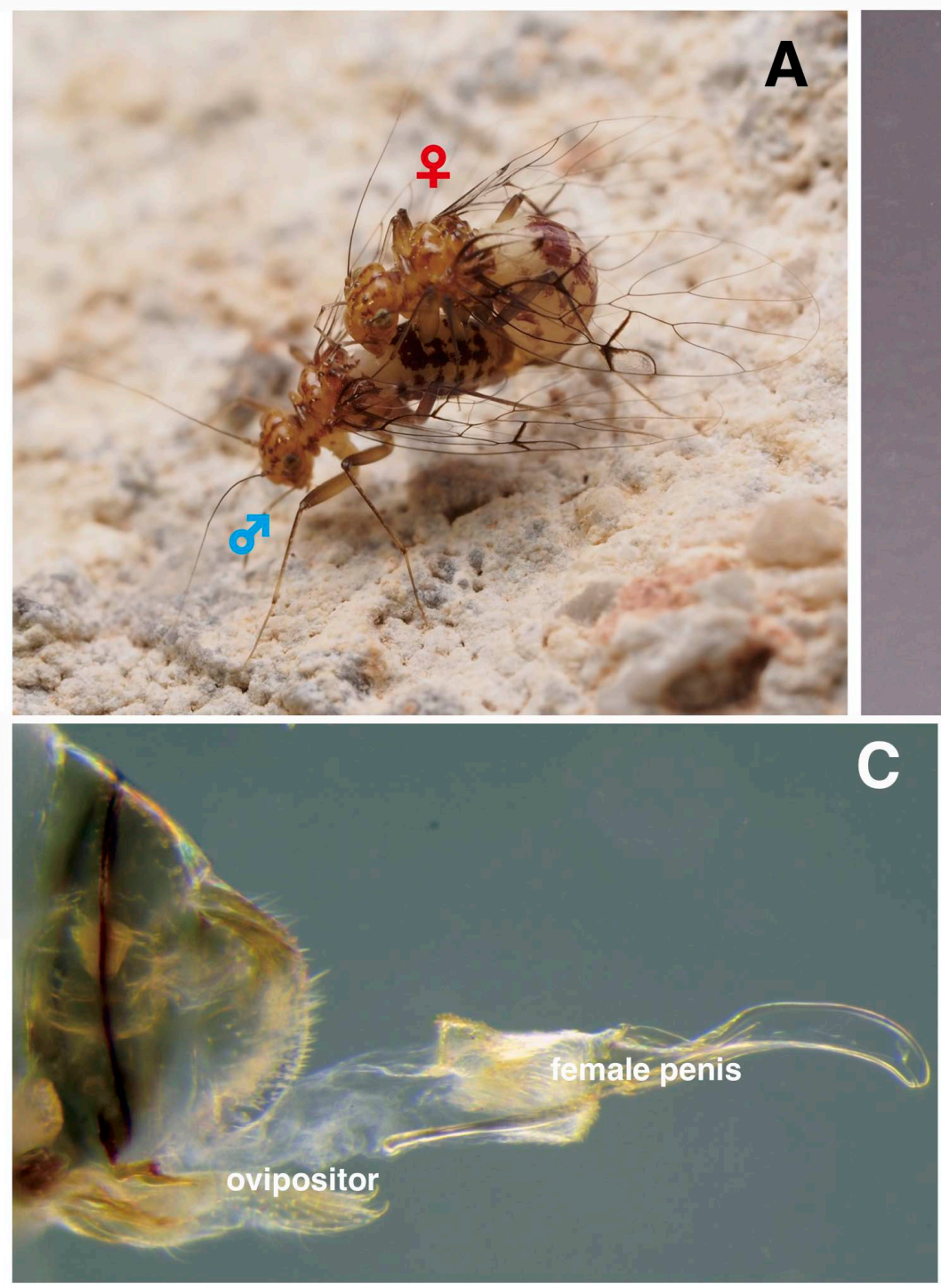
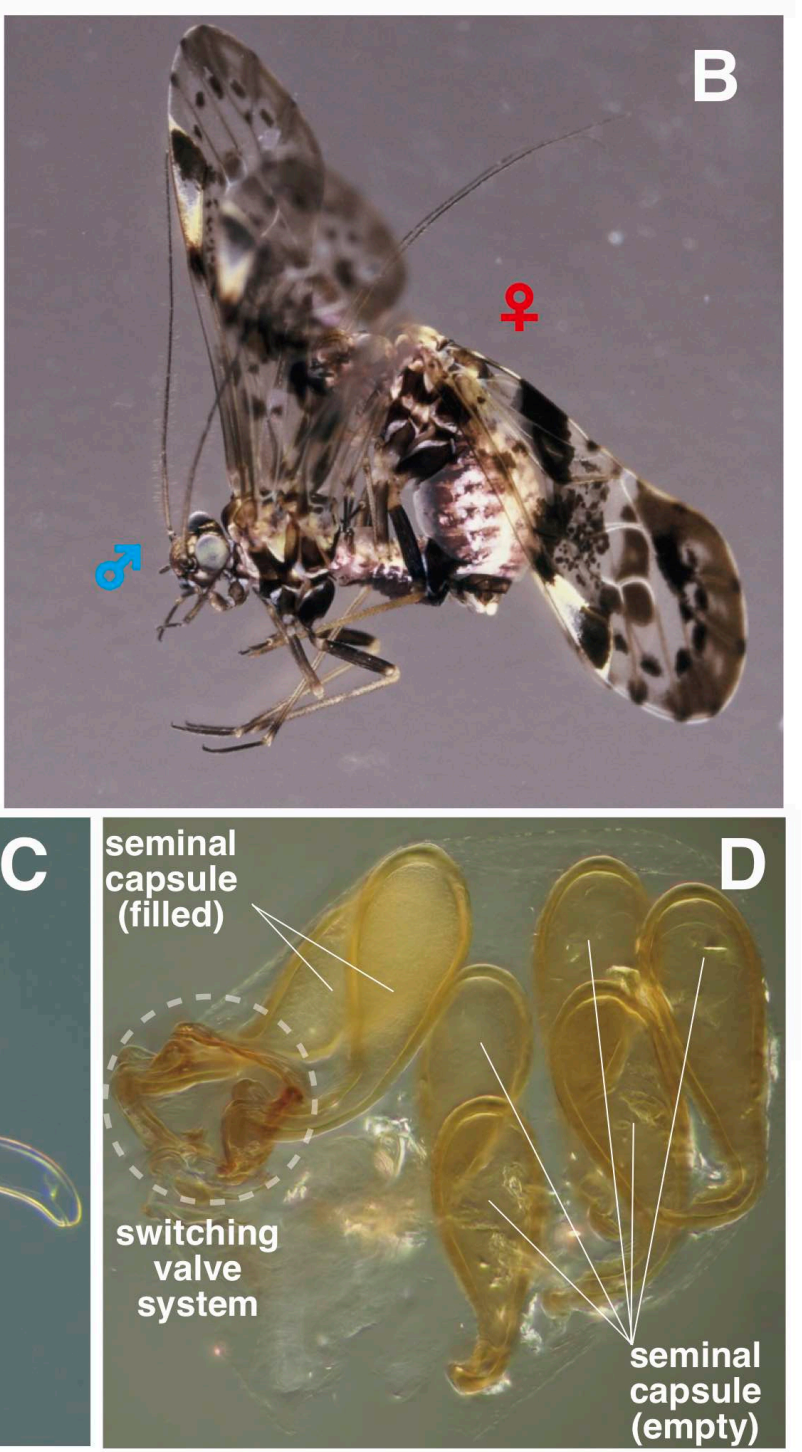


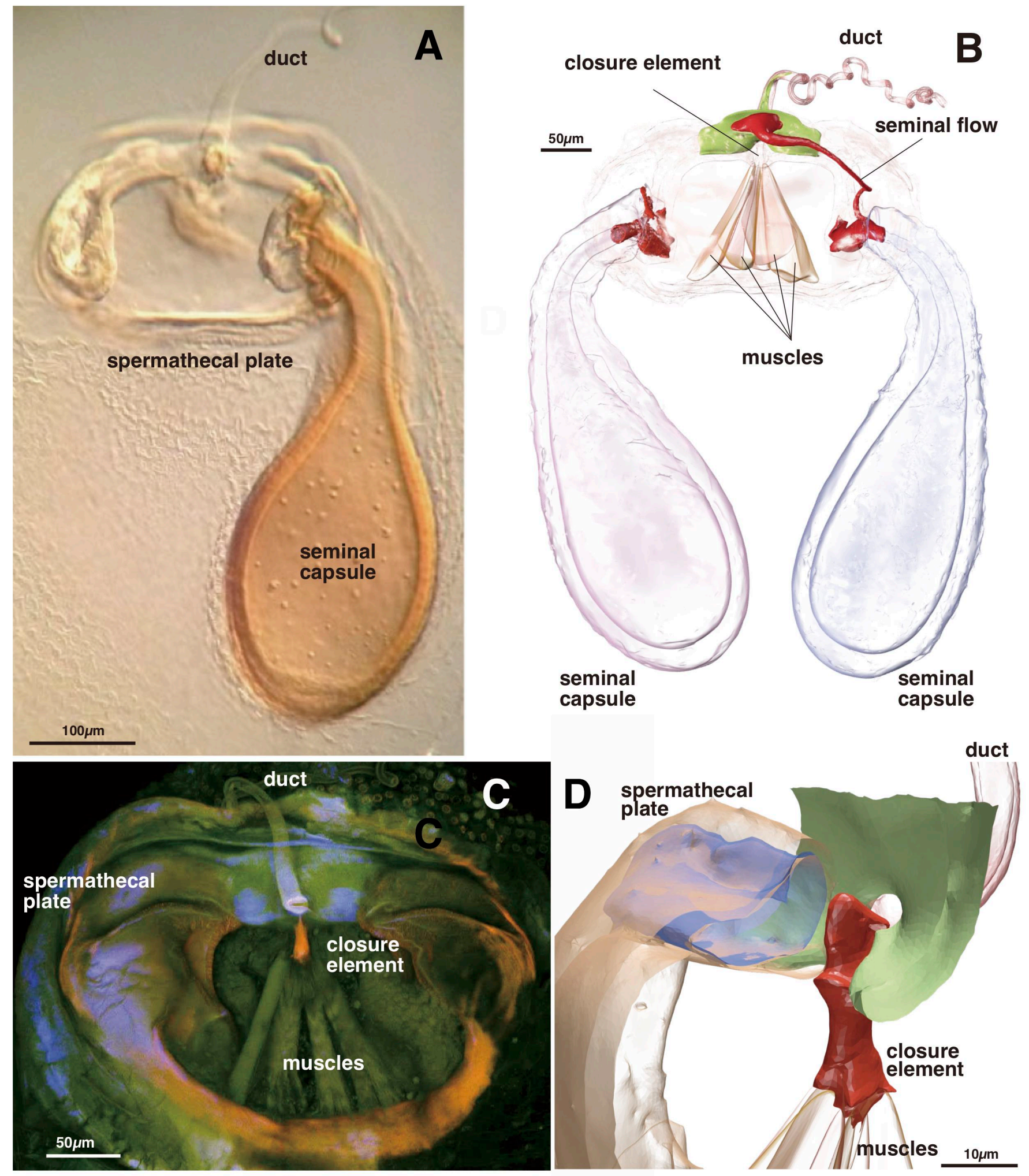



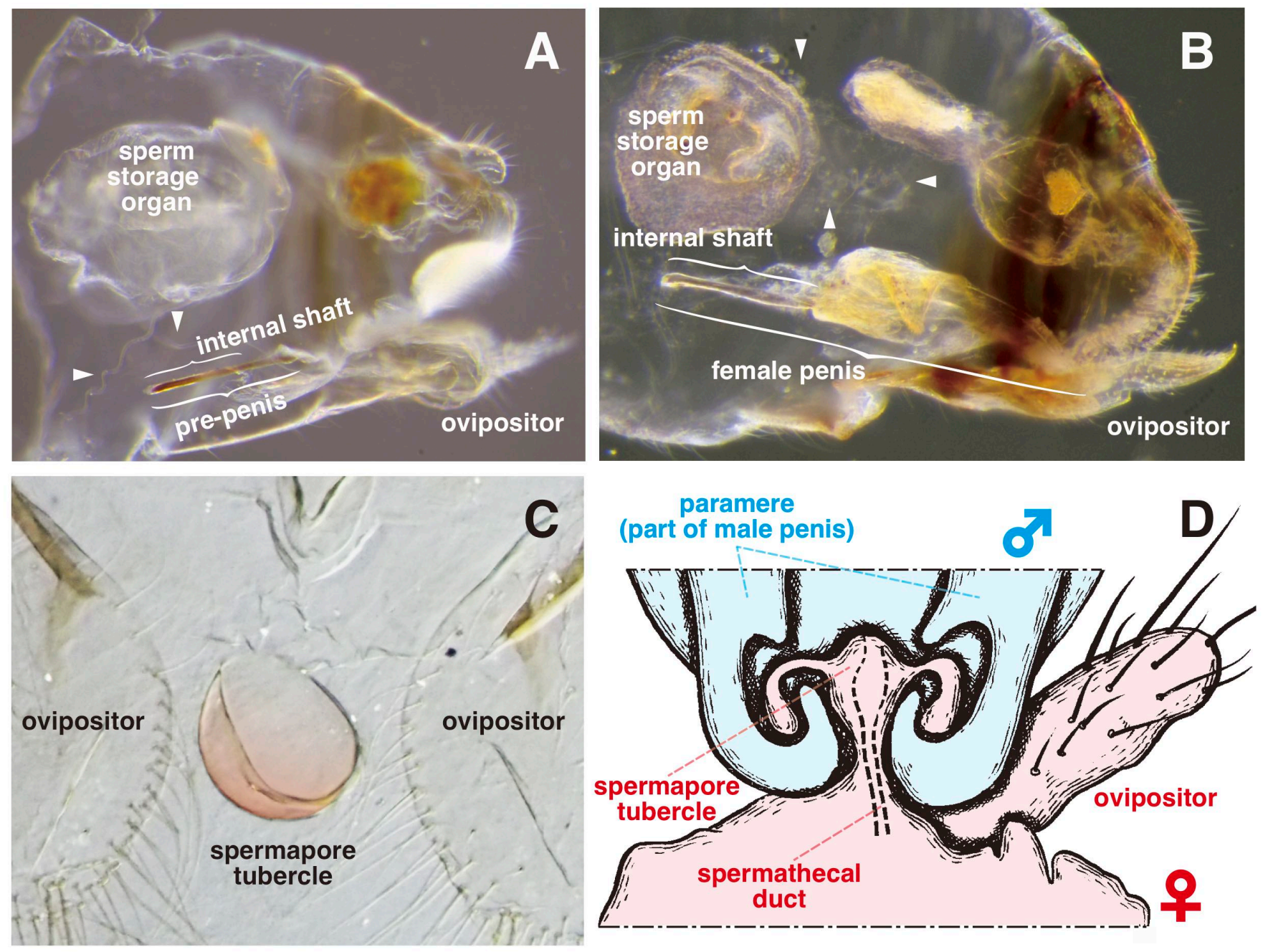